\title{
A probabilistic assessment of the effect of post-weld treatment on the fatigue performance of tubular truss bridges
}

\author{
Scott Walbridge ${ }^{\mathrm{a}, *}$, Alain Nussbaumer ${ }^{\mathrm{b}}$ \\ ${ }^{a}$ Department of Civil and Environmental Engineering, University of Waterloo, 200 University Avenue West, Waterloo, Ontario N2L $3 G 1$, Canada \\ ${ }^{\mathrm{b}}$ Swiss Federal Institute of Technology (EPFL), Steel Structures Laboratory (ICOM), Building GC B3 - Office 505, Station 18, Lausanne, CH-1015, Switzerland
}

Received 4 July 2006; received in revised form 28 March 2007; accepted 30 March 2007

Available online 8 May 2007

\begin{abstract}
In the design of tubular truss bridges, engineers have found the fatigue performance of the joints to be a critical aspect. In looking for ways to improve this performance, the use of residual stress-based post-weld treatments has been suggested. Although these treatments have been shown to increase the average fatigue lives of welded details under constant amplitude loading conditions in a number of studies, concerns exist regarding their reliability, in particular under realistic, variable amplitude loading conditions. With this in mind, the effect of post-weld treatment on the fatigue performance of tubular truss bridges is assessed herein using a previously developed probabilistic, fracture mechanics-based model, modified to analyze entire bridge structures under realistic, variable amplitude loading conditions. This model uses a systems reliability approach to consider the influences of the various potential crack sites on the overall reliability of the bridge. By analyzing several variants of a typical tubular truss bridge, it is shown that post-weld treatment can result in a significant fatigue performance improvement for this bridge type. This improvement is quantified herein in terms of either a savings in steel weight or an increase in fatigue life. Several additional studies examine the sensitivity of the results of this assessment to variations in the treatment coverage, intensity, and uniformity. These studies show that similar results can be obtained with a partial treatment strategy to those observed when the entire bridge is treated, and that the treatment benefit depends more on the intensity than the uniformity of the treatment.
\end{abstract}

(C) 2007 Elsevier Ltd. All rights reserved.

Keywords: Steel; Tubular truss bridges; Fatigue; Post-weld treatment; Fracture mechanics; Reliability

\section{Introduction}

A number of landmark vehicular bridges have been constructed in recent years, primarily in continental Europe, wherein the main support structure has consisted of large steel tubes welded together to form truss girders [1-3]. The merits of this bridge type are discussed in a number of references (i.e.: [2-4]). One of the often cited weaknesses is the characteristically low fatigue performance of their joints.

In the fatigue design of tubular truss bridges, civil engineers have tended to rely heavily on tubular joint research conducted for the offshore industry. Concerns about the validity of this approach, in view of the significant differences in loading, scale, and geometry that exist between offshore structures and

\footnotetext{
* Corresponding author. Tel.: +1 519888 4567x38066; fax: +1 5198884349

E-mail address: swalbrid@ civmail.uwaterloo.ca (S. Walbridge).
}

bridges, have led to recent specialized research on tubular bridge joints. This research has including a number of largescale fatigue tests on circular hollow section (CHS) $K$-joints with dimensions commonly found in bridge structures (i.e. $\gamma=$ $D /(2 \cdot T) \leq 12$-see Fig. 1) [4,5].

In looking for ways of improving the fatigue performance of tubular bridge joints, two possibilities have received recent attention: replacing the directly welded joints with cast steel nodes, thereby moving the fatigue-critical welds away from the severe geometric discontinuities associated with the joint and allowing additional steel to be concentrated where it is needed most (i.e.: [6,7]), and improving the performance of the fatiguecritical welds, where they are, through the use of post-weld treatment (PWT) methods. The second possibility is examined herein.

Post-weld treatment methods are typically divided into two categories: geometry improvement methods (such as burr/disc 


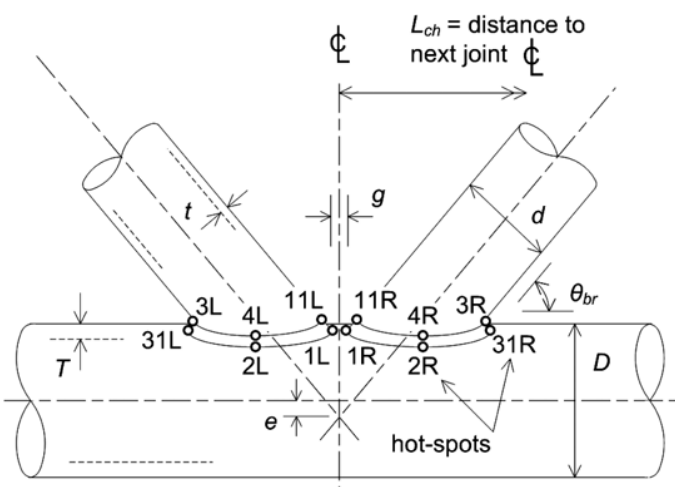

Fig. 1. Non-overlapping single $K$-joint.

grinding and TIG/plasma dressing) and residual stress-based methods (such as needle/hammer peening and ultrasonic impact treatment). The mechanisms employed by the various methods, as well as their potential benefits, advantages, and disadvantages are discussed in a number of references (i.e.: [8-14]).

As part of the research on tubular bridge joints presented in $[4,5]$, several fatigue tests were carried out on tubular joints that had been post-weld treated by needle peening. These tests showed that, under constant amplitude (CA) loading conditions, needle peening could result in an improvement in fatigue strength of over $60 \%$, or in terms of fatigue life, an improvement of over four times. Although encouraging, several concerns with the use of residual stress-based treatment methods such as needle peening have limited the extent to which results such as these can be translated into practical guidelines. Firstly, there is some concern in general about the reliability of these treatment methods, in particular under realistic, variable amplitude (VA) loading conditions [12,13]. Secondly, in the tests cited above, it was seen that the benefit of concentrated treatment of the critical crack site, although substantial, was eventually limited by cracking at a less critical, untreated site.

To address these concerns, a study was initiated to investigate the post-weld treatment of tubular truss bridges in greater depth, using a probabilistic linear elastic fracture mechanics (LEFM)-based approach [14-17]. The available test results from $[4,5]$ were used to calibrate certain parameters needed to apply the probabilistic model for single crack sites used in this work. A systems reliability approach was then used to consider the influences of the various potential crack sites on the overall fatigue reliability of tubular structures with multiple potential crack sites. The resulting model was then used to demonstrate that, under CA loading conditions, significant improvements in the fatigue performance of tubular bridge joints can be achieved with post-weld treatment, even when the influences of the various potential crack sites on the overall reliability of the joint are considered [15].

Herein, modifications to the probabilistic model developed in $[14,15]$ to facilitate the analysis of entire tubular truss bridges under realistic, VA loading conditions are presented. In order to assess the benefit of post-weld treatment for this bridge type, a number of variants of a typical tubular truss bridge were designed, as discussed in [14], with differing levels of "under- design" for fatigue. Based on the results of analyses conducted for the different bridge variants (untreated and treated), the potential benefit of post-weld treatment is quantified herein in terms of either a savings in steel weight or an increase in fatigue life. A number of additional studies are then presented, which allow the effects of variations in the treatment coverage, intensity, and uniformity to be characterized.

The work presented herein focuses on the post-weld treatment by needle peening of tubular truss bridges comprised of CHS members joined by welded, non-overlapping single $K$ joints (see Fig. 1). However, it is believed that the employed approach is applicable to tubular structures treated using any of the above-mentioned residual stress-based methods. Needle peening is considered to be relatively mild, compared to the other common residual stress-based methods. Non-overlapping $K$-joints are a common joint type for tubular truss bridges. This is thought to be primarily due to the complexities involved with cutting the diagonals for overlapping $K$-joints, in particular for bridges consisting of space trusses joined with double $K$ - or " $K K$-" joints (i.e.: [1-3]).

\section{Probabilistic LEFM-based model}

The probabilistic model for single crack sites employed herein is based on a previously developed deterministic LEFM model [18], modified for the analysis of crack sites in CHS $K$-joints. The modified model employs a number of design aids developed by other researchers [4,19-22] to determine the applied stress intensity factor (SIF) ranges at various crack depths for weld toe cracks at the various potential crack sites or hot-spots on such joints. For each hot-spot, the required input includes: the initial defect depth, $a_{0}$, and shape, $(a / c)_{0}$, the critical crack depth, $a_{c}=(t$ or $T) / 2$, the crack propagation parameters: $C, m$, and $\Delta K_{t h}$, the various parameters describing the joint geometry (see Fig. 1), the weld angle and footprint length, $\theta_{w}$ and $L_{w}$, and the hot-spot stress range, $\Delta \sigma_{h s, a p p}$, and ratio, $R$.

In the probabilistic model, $a_{c}, m$, and the joint geometry parameters are treated deterministically, while the parameters $a_{0},(a / c)_{0}, C$, and $\Delta K_{t h}$ are described by statistical variables. Several additional statistical variables are introduced to consider the uncertainties associated with: the hot-spot stress range and ratio, the weld angle and footprint length, and a number of other parameters contained in the crack growth law employed by the model, including the magnification and correction factors, $M k$ and $Y$, stress concentration factor, SCF, and degree of bending, DOB (see Appendix).

In order to analyze post-weld treated potential crack sites, the model employed herein assumes that treatment methods such as needle peening work primarily by introducing compressive residual stresses near the treated surface. These stresses have the effect of reducing crack growth rates in the early part of the stable growth phase of the total fatigue life. Other effects of the treatment, such as the possible beneficial smoothing of the discontinuity at the weld toe, the potentially detrimental introduction of small notch-like dents, the beneficial flattening and aligning of the surface 


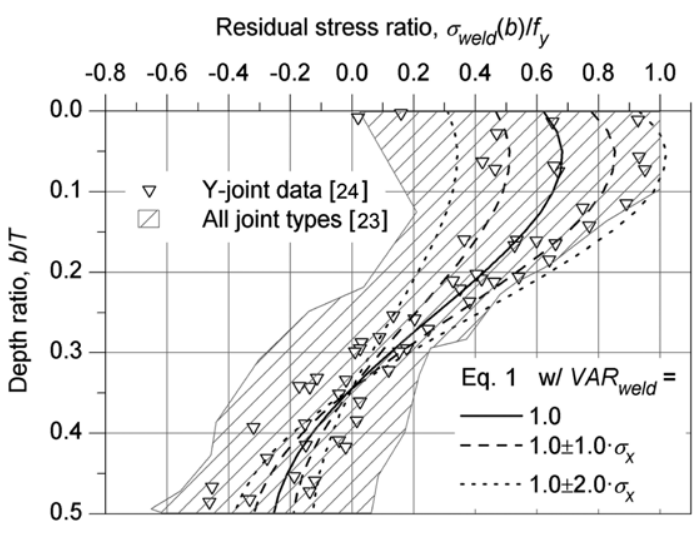

Fig. 2. Eq. (1) compared with measured residual stresses due to welding from $[23,24]$.

grains etc., are all assumed to have an influence that is either negligible or small but beneficial. This assumption is supported by crack propagation measurements on untreated and treated details reported by others [18] and thought to be particularly appropriate for welded details, which tend to have crack-like defects present prior to the application of the first load cycle and thus practically no crack initiation phase $[14,15,18]$.

In the model, the uncertainties in the residual stress distributions due to the welding and post-weld treatment processes, $\sigma_{\text {weld }}(b)$ and $\sigma_{p w t}(b)$, are represented by two statistical variables, $V A R_{\text {weld }}$ and $V A R_{p w t}$, which are assigned attributes based on stress measurements reported in [18,23,24].

The assumed residual stress distribution due to the welding process is as follows $[14,15]$ :

$$
\begin{aligned}
\sigma_{\text {weld }}= & f_{y} \cdot\left(0.620+2.327 \cdot(b / T)-24.125 \cdot(b / T)^{2}\right. \\
& \left.+42.485 \cdot(b / T)^{3}-21.087 \cdot(b / T)^{4}\right) \cdot V A R_{\text {weld }}
\end{aligned}
$$

where $b$ is the depth below the surface and $T$ is the wall thickness of the cracked member. This distribution is based on measurements made on welded tubular joint specimens [23,24].

The assumed post-weld treatment residual stress distribution is:

$$
\begin{aligned}
\sigma_{p w t}(b)= & -f_{y} \cdot\left(V A R_{p w t}\right) \quad \text { if } b \leq 0.1 \cdot d_{p} \\
= & f_{y} \cdot\left(\left(b / d_{p}\right) \cdot(5 / 6)-\left(1 / 12+V A R_{p w t}\right)\right) \\
& \text { if } b>0.1 \cdot d_{p}
\end{aligned}
$$

where $d_{p}$ is the imprint diameter of the peening tool $(1.5 \mathrm{~mm}$ for needle peening). To determine the combined (welding plus treatment) stress distribution, the parameter PWT is introduced, such that:

$$
\begin{aligned}
\sigma_{\text {res }}(b) & =\operatorname{MIN}\left(\sigma_{p w t}(b), \sigma_{\text {weld }}(b)\right) \quad \text { if PWT }=1 \\
& =\sigma_{\text {weld }}(b) \quad \text { if } \mathrm{PWT}=0 .
\end{aligned}
$$

The assumed residual stress distributions are compared with the measurements on which they were based in Figs. 2 and 3. Using these measurements, the parameters describing the $V A R_{\text {weld }}$ and $V A R_{p w t}$ statistical variables were determined using the maximum likelihood method, as discussed in $[14,15]$. In the case of the treatment stress measurements reported in [18], the parameters were calibrated using only the measurements

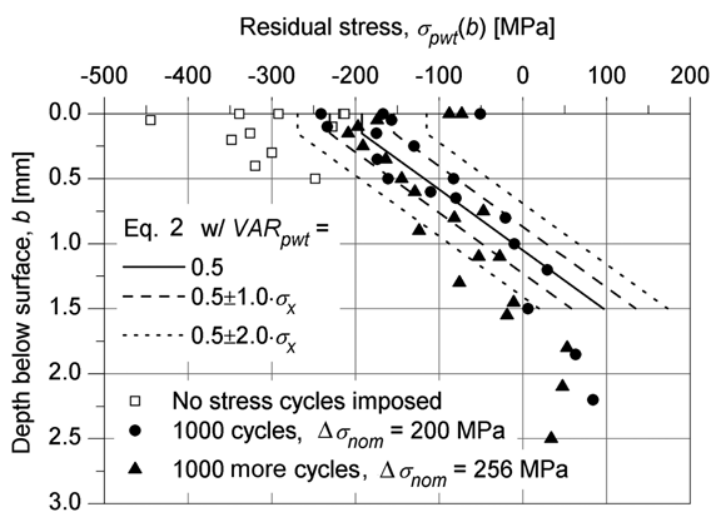

Fig. 3. Eq. (2) compared with measured residual stresses due to needle peening from [18].

made after a number of cycles at the indicated nominal stress range (see Fig. 3) had been applied to consider the possibility of residual stress relaxation. It should be noted that longitudinally stiffened steel plate specimens were used in [18]. Details are given in Appendix regarding the manner in which residual stresses are considered in the crack growth law employed by the model.

In order to analyze tubular structures with multiple potential crack sites, a systems reliability approach is employed, wherein the entire tubular joint or truss is considered as a simple series system [25]. Using this approach, reliability bounds can be calculated for tubular structures (i.e. joints and/or entire bridges) assuming no (lower bound) and full (upper bound) correlation between the probabilities of failure of the various potential crack sites in the structure (see Appendix and $[14,15]$ ).

The model described above was first used to predict the fatigue performances of the untreated and treated tubular joint specimens tested in $[4,5]$ under CA loading conditions, as discussed in $[14,15]$. Using values suggested in the literature for the various input parameters and statistical variables, the model was shown to accurately predict the shift in the critical crack site due to the post-weld treatment observed in the tests. The model was also seen to closely predict the fatigue lives of the untreated specimens, while slightly over-predicting the increase in fatigue life due to the post-weld treatment. By calibrating the mean values for the $(a / c)_{0}, C$, and $\Delta K_{t h}$ statistical variables, again using the maximum likelihood method, this discrepancy could be explained. It should be noted that the calibrated mean values for these variables still fell within the range of mean values suggested in the literature $[14,15]$.

\section{Analysis of full-scale structures under realistic loading conditions}

In order to apply the probabilistic model described in the previous section to entire bridges under realistic loading conditions, it was necessary to incorporate a number of additional elements. Firstly, for the analysis of the tubular joint specimens, the hot-spot stresses could be obtained using strain gauge data. At locations in the joint where no such data was available, these stresses could alternatively be determined by multiplying the nominal member stresses (for which the needed 


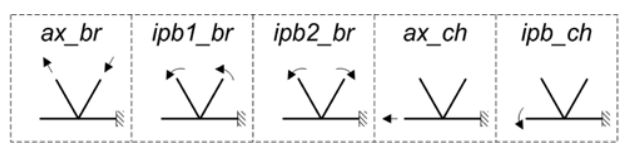

Fig. 4. Nominal member load cases.

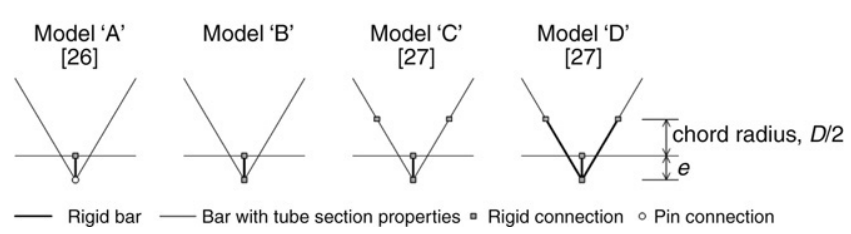

Fig. 5. Candidate joint models.

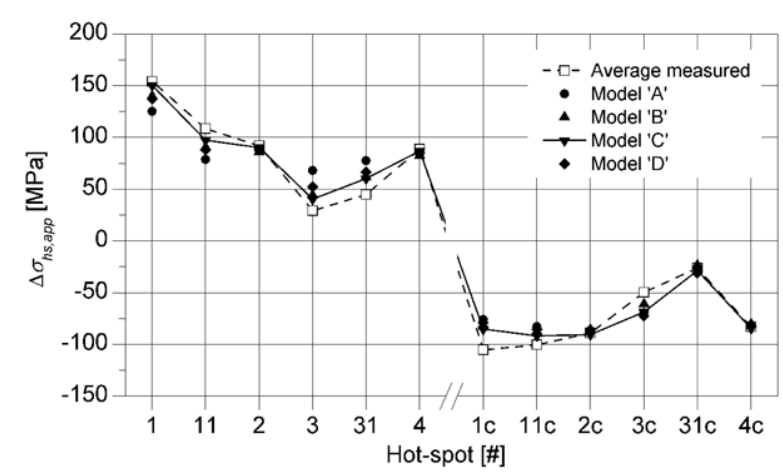

Fig. 6. Comparison of joint models and measured data for $K$-joint specimens from [4].

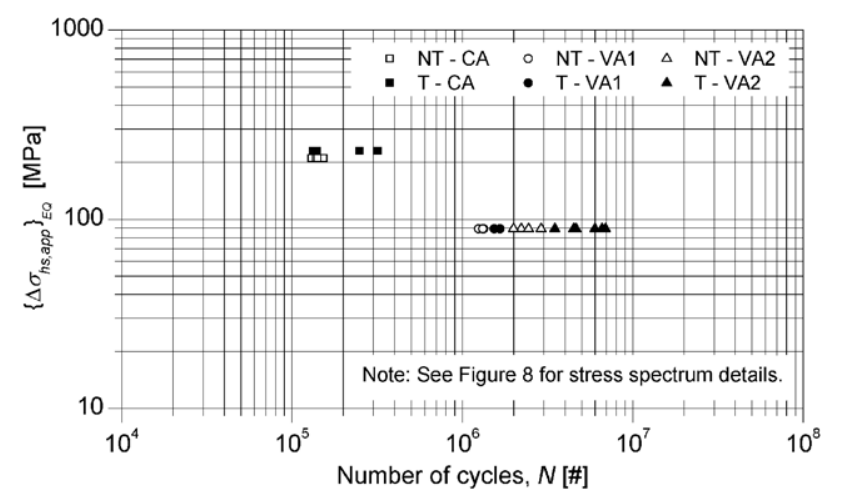

Fig. 7. Variable amplitude loading fatigue test results from [12].

strain gauge data was always available), by SCFs obtained from the tables developed in [4] for CHS $K$-joints with $\gamma=$ $D /(2 \cdot T) \leq 12$. SCFs are provided in [4] for each of the hotspots in Fig. 1 and each of the five simple nominal member load cases in Fig. 4.

Given the nominal member stresses, the hot-spot stress is obtained using the following expression:

$$
\begin{aligned}
\sigma_{h s, a p p}= & \sigma_{a x \_b r} \cdot \mathrm{SCF}_{a x_{-} b r}+\sigma_{a x_{-} c h} \cdot \mathrm{SCF}_{a x_{\_} c h} \\
& +\sigma_{i p b 1 \_b r} \cdot \mathrm{SCF}_{i p b 1 \_b r}+\sigma_{i p b 2 \_b r} \cdot \mathrm{SCF}_{i p b 2 \_b r} \\
& +\sigma_{i p b_{\_} c h} \cdot \mathrm{SCF}_{i p b_{-} c h}
\end{aligned}
$$

where $\sigma_{a x \_b r}$ is the nominal member stress due to balanced axial brace load case and $\mathrm{SCF}_{a x \_b r}$ is the corresponding stress concentration factor, etc. It should be noted that for some hotspots, the contributions of certain load cases may be negligible (for example, the chord loading cases, ax_ch and ipb_ch, may have little effect on the hot-spot stresses for the brace-side hotspots 11, 3, and 4-see Fig. 1). In applying Eq. (4), this is taken into consideration automatically, however, in the SCF values from [4].

In the case of structures for which no strain gauge data is available, the nominal member stresses can be determined by structural analysis. To do this, however, a suitable structural model of the joint is needed. Fig. 5 shows four candidate joint models that were considered for use in this study. In Fig. 6, hot-spot stresses predicted using each model $[26,27]$ are compared with corresponding hot-spot stresses determined using the measured nominal strains reported in [4]. Based on such comparisons, Model ' $\mathrm{C}$ ' from [27] was adopted in the current study. Models of greater complexity than those shown in Fig. 6 can be envisioned (i.e. including spring elements to better model the stiffness of the joint, etc.). However, Model ' $\mathrm{C}$ ' was thought to be an acceptable compromise between accuracy and simplicity, and thus well suited for the purpose of conducting structural analysis to determine the nominal member stresses.

For the analysis of the test specimens, it was possible to measure the weld geometry parameters, $L_{w}$ and $\theta_{w}$, directly on specimens sectioned after testing. For the analysis of entire tubular bridges, another method of obtaining the values for these parameters was needed. Towards this end, a set of parametric equations was developed in [14] for estimating the weld geometry parameters, $L_{w}$ and $\theta_{w}$, at the various potential crack sites in CHS $K$-joints based on the minimum dimensions specified in [28].

In order to analyze tubular bridges under realistic, VA loading conditions, modifications to the adopted deterministic crack propagation model were required. Specifically, a simple crack closure model was needed that would give accurate crack growth predictions for untreated and treated details under VA loading conditions. In [12], the fatigue behaviour of as-welded and needle peened longitudinal plate stiffener specimens was investigated under one CA and two VA stress spectrums. The test results from this investigation are summarized in Fig. 7. In this figure, the results for the as-welded specimen are denoted ' $N T$ ' (not treated) and those for the peened specimen are denoted ' $T$ ' (treated).

A number of methods for predicting crack growth rates under variable amplitude loading are summarized in [29]. Among the simpler of these are the equivalent CA stress range and equivalent block loading methods, also discussed in [30]. These will be referred to hereafter as Methods 1 and 2 respectively. $[12,13]$ found that fatigue life predictions made using the Method 1 (i.e. using an equivalent CA stress range determined based on the Palmgren-Miner sum) tend to be relatively accurate for untreated specimens, but often highly unconservative for treated specimens. With this in mind, Method 2 was employed in the current study. According to this method, the variable amplitude stress spectrum is divided into several CA stress range blocks. At each crack depth, $a$, the crack closure stress due to each block is calculated. The rate of 

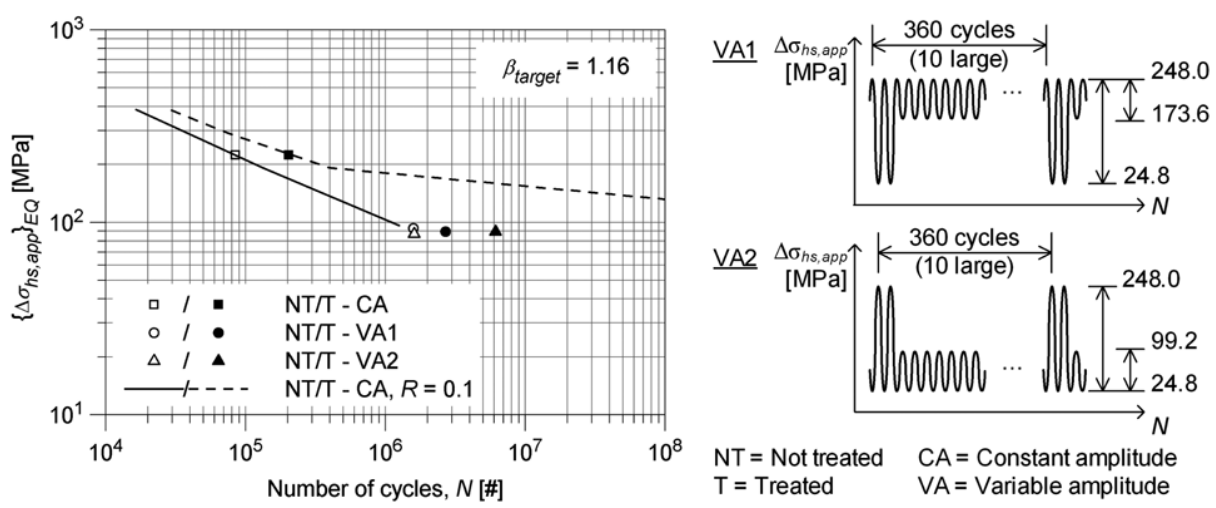

Fig. 8. Simulation of tests reported in [12] using probabilistic model.

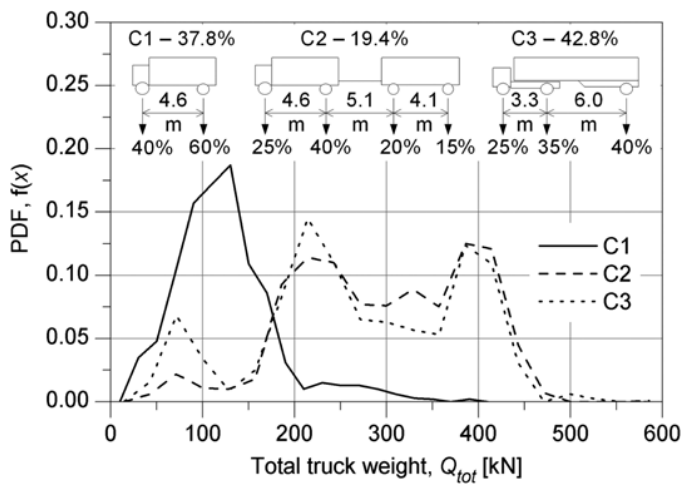

Fig. 9. Traffic model used in probabilistic analysis.

crack growth is then determined by calculating the damage due to each CA stress range block, assuming a crack closure stress for all blocks in the spectrum equal to the largest crack closure stress caused by any one of the blocks at that crack depth.

Although the adopted model is somewhat simplistic compared to some of the available alternatives, it was expected to capture the major trends observed in fatigue tests under VA loading conditions. This can be seen by comparing the test results and probabilistic model predictions under VA loading conditions in Fig. 7 and Fig. 8 respectively. In Fig. 8, the equivalent CA stress range, determined using the Palmgren-Miner sum, is plotted on the vertical axis versus the number of cycles required to cause the reliability of the detail to decrease to a given value ( $\beta=1.16$ in this case), according to the probabilistic model (which uses Method 2). Comparing Figs. 7 and 8, similar trends can be seen. Specifically, the probabilistic model accurately predicts that the fatigue life should be greater for the treated specimens under spectrum VA2 than under VA1, even though they both have the same equivalent $\mathrm{CA}$ stress range. The curves in Fig. 8 are $\mathrm{S}-\mathrm{N}$ curves for the untreated and treated details under CA loading conditions, calculated using the probabilistic model (note: the applied and equivalent $\mathrm{CA}$ stress ranges are one and the same under CA loading). As can be seen by comparing these curves with the data points for the two VA stress spectra, predictions made using an equivalent CA stress range (Method 1) would be fairly accurate for the untreated details, but highly unconservative for the treated details. This corresponds well with the findings of $[12,13]$.

Although the adopted model is seen to capture the major trends observed in $[12,13]$, it does not predict the reduction in fatigue performance that would occur due to the application of large compressive overloads, which have the effect of flattening the crack faces near the crack tip, and thus reducing the crack closure SIF. According to [29], this omission can have serious implications for structures, such as airframes, which experience frequent compressive overloads. For structures subjected primarily to narrow band, Gaussian load spectra such as bridges, however, this omission is thought to be much less severe.

The last piece of information needed to model bridges under realistic loading conditions was a suitable traffic model. The model adopted herein consists of three truck types, with weight distributions as shown in Fig. 9. The contribution of each truck type to the total traffic volume is also indicated in this figure. This model is based on weigh scale measurements taken on the main highway between Bern and Zurich, Switzerland (see [31]), modified as discussed in [14] to reflect the recent increase in the legal truck weight limit in Switzerland from 28 to 40 tonnes. In applying this model, the indicated truck weights are multiplied by a deterministic dynamic factor of 1.3. The adopted traffic model does not consider the simultaneous crossing of conveys or trucks travelling in opposite directions, nor does it consider the evolution of truck weights and traffic volumes over time. Despite these shortcomings, the use of this model, and the analysis of the resulting VA stress spectrums using the equivalent block loading method (Method 2 ), is expected to provide a significant improvement over the equivalent CA stress range method (Method 1) for evaluating the effects of post-weld treatment on fatigue performance.

With the additional elements described above, the analysis of single hot-spots in tubular truss bridges under realistic, VA loading conditions can be performed. No changes to the adopted series system reliability models for structures with multiple potential crack sites are required. In the probabilistic assessment presented in the following sections, the distributions given in Table 1 for the statistical variables are used. In this table, the VAR variables are typically factors by which the parameters described by the subscripts are multiplied. The applied stresses due to the traffic and dead loads, for example, 
Table 1

Statistical variables

\begin{tabular}{|c|c|c|c|c|c|}
\hline Variable & $i$ & $\mu_{x}$ & $\sigma_{x}$ & Dist. & Units \\
\hline$a_{0}$ & 1 & 0.2 & 0.045 & LN & $\mathrm{mm}$ \\
\hline$(a / c)_{0}$ & 2 & 0.5 & 0.16 & LN & - \\
\hline$V A R_{\text {traffic }}$ & 3 & 1.0 & 0.15 & $\mathrm{~N}$ & - \\
\hline$V A R_{\text {dead }}$ & 4 & 1.0 & 0.10 & $\mathrm{~N}$ & - \\
\hline$V A R_{D O B}$ & 5 & 1.0 & 0.08 & $\mathrm{~N}$ & - \\
\hline$V A R_{S C F}$ & 6 & 1.0 & 0.04 & LN & - \\
\hline$V A R_{M k}$ & 7 & 1.0 & 0.05 & LN & - \\
\hline$V A R_{L w}$ & 8 & 1.0 & 0.10 & $\mathrm{~N}$ & - \\
\hline$V A R_{\theta w}$ & 9 & 1.0 & 0.10 & $\mathrm{~N}$ & - \\
\hline$V A R_{\text {weld }}$ & 10 & 1.0 & 0.25 & $\mathrm{~N}$ & - \\
\hline$V A R_{p w t}$ & 11 & 0.5 & 0.10 & $\mathrm{~N}$ & - \\
\hline $\mathrm{LN}(C)$ & 12 & -28.80 & 0.55 & $\mathrm{~N}$ & $\mathrm{LN}\left((\mathrm{mm} /\right.$ cycle $\left.) \cdot\left(\mathrm{N} / \mathrm{mm}^{-3 / 2}\right)^{m}\right)$ \\
\hline$\Delta K_{t h}$ & 13 & 100.0 & 15.0 & $\mathrm{LN}$ & $\mathrm{MPa} \sqrt{ } \mathrm{mm}$ \\
\hline$a_{c}$ & - & $0.5 \cdot T$ & - & det. & $\mathrm{mm}$ \\
\hline$f_{y}$ & - & 355 & - & det. & $\mathrm{MPa}$ \\
\hline$m$ & - & 3.0 & - & det. & - \\
\hline
\end{tabular}
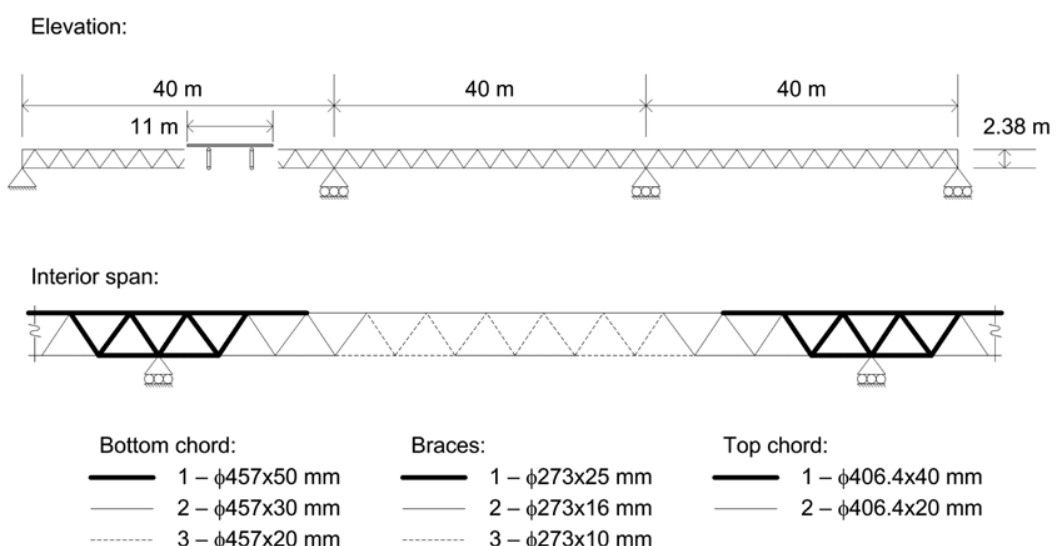

Fig. 10. Bridge I - designed for static strength.

are multiplied by the variables: VAR traffic and VAR dead. Further details regarding these variables can be found in [14].

\section{Description of analyzed tubular truss bridge}

Using the model described in the previous section, a probabilistic assessment was carried out of a typical composite tubular truss bridge. The geometry of the studied bridge is presented in Fig. 10. A variant (I) of the bridge was first designed to meet the static strength and serviceability requirements of the Swiss Design Codes [32]. These codes are based on the same principles as the Eurocodes [33], and thus result in similar designs. As a simplification, no interaction or load sharing was considered between the two trusses comprising the bridge (i.e. each truss was assumed to support half of the dead and half of the traffic load). For the tests on tubular bridge joints presented in $[4,5]$, the tubular truss specimens were constructed from hot-finished tubes of grade S 355 steel conforming to EN 10210-1:1994 and EN 102102:1997 (see [4]). A similar steel grade was assumed for the truss bridge studied herein. The member dimensions were limited to standard tubular section sizes available in Europe.
A second bridge variant (V) was then designed to meet the fatigue requirements of these codes, assuming: a planned service life of 70 years (imposed by the Swiss Codes note: this is, in fact, the only significant difference with the Eurocodes, which specify a planned service life of 100 years), a 40 tonne legal truck weight limit, and bidirectional principal road traffic $\left(5 \times 10^{5}\right.$ trucks/dir./year $)$. For this design, the bridge was assumed to be untreated and a hot-spot stress verification was employed using the SCFs and recommended hot-spot S-N curve from [4]. The result was a significant increase in the steel weight over that of the first bridge variant. Three intermediate variants (II-IV) were then conceived with varying levels of under-design for fatigue. With the resulting five bridge variants (see Table 2), it was thought that the potential benefit of post-weld treatment could be precisely determined.

\section{Analysis of untreated and treated bridge variants}

In order to characterize the fatigue reliability of each bridge variant, 72 hot-spots on half of the interior span of one truss were analyzed using the probabilistic single site model. 
Table 2

Five bridge variants studied

\begin{tabular}{|c|c|c|c|c|c|c|}
\hline \multirow{2}{*}{$\frac{\text { Bridge }}{\text { Description }}$} & & \multirow{2}{*}{$\begin{array}{l}\text { I } \\
\text { Designed for static strength }\end{array}$} & II & III & IV & \multirow{2}{*}{$\frac{\mathrm{V}}{\text { Designed for fatigue }}$} \\
\hline & & & Intermedis & gns & & \\
\hline \multirow{3}{*}{ Bottom chord } & 1 & $457 \times 50^{\mathrm{a}}$ & $457 \times 50$ & $457 \times 60$ & $508 \times 70$ & $559 \times 80$ \\
\hline & 2 & $457 \times 30$ & $457 \times 36$ & $457 \times 60$ & $508 \times 70$ & $559 \times 80$ \\
\hline & 3 & $457 \times 20$ & $457 \times 36$ & $457 \times 60$ & $508 \times 70$ & $559 \times 80$ \\
\hline \multirow{3}{*}{ Braces } & 1 & $273 \times 25$ & $273 \times 25$ & $273 \times 30$ & $323.9 \times 35$ & $355.6 \times 40$ \\
\hline & 2 & $273 \times 16$ & $273 \times 16$ & $273 \times 20$ & $323.9 \times 25$ & $355.6 \times 30$ \\
\hline & 3 & $273 \times 10$ & $273 \times 10$ & $273 \times 16$ & $323.9 \times 20$ & $355.6 \times 25$ \\
\hline \multirow{2}{*}{ Top chord } & 1 & $406.4 \times 40$ & $457 \times 50$ & $457 \times 60$ & $508 \times 70$ & $559 \times 80$ \\
\hline & 2 & $406.4 \times 20$ & $457 \times 36$ & $457 \times 60$ & $508 \times 70$ & $559 \times 80$ \\
\hline \multirow{2}{*}{ Steel weight } & $\mathrm{kN} / \mathrm{m}^{\mathrm{b}}$ & 8.8 & 10.9 & 15.4 & 19.7 & 24.3 \\
\hline & $\%$ of total wt. ${ }^{\mathrm{c}}$ & 11.1 & 13.4 & 17.9 & 21.8 & 25.7 \\
\hline
\end{tabular}

\footnotetext{
a All tube dimensions in $\mathrm{mm}$.

${ }^{\mathrm{b}}$ One truss only, including $20 \%$ of Bridge I steel weight as allowance for transverse elements.

$\mathrm{c} \%$ of total weight $=($ total steel weight/total bridge weight $) \cdot 100 \%$.
}

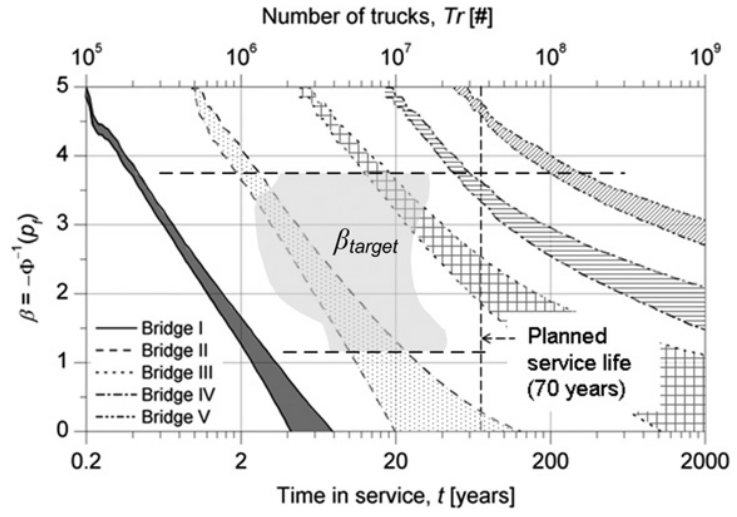

Fig. 11. Reliability envelopes for untreated bridge variants.

Each hot-spot was analyzed with and without treatment. The reliability of the interior truss span was then calculated with various levels of treatment coverage assumed by combining the results for the individual untreated and treated hot-spots in different ways.

The results of the probabilistic analyses for each of the five untreated bridge variants are presented in Fig. 11. In this figure, along with the reliability envelopes for each variant, the planned service life (70 years) is indicated, as well as a target fatigue reliability index range $\left(1.16 \leq \beta_{\text {target }} \leq\right.$ 3.74) based on the recommendation of the Eurocodes for a 70 year service life [33]. This $\beta_{\text {target }}$ range suggests that fatigue cracking is considered in these codes to be somewhere between a serviceability and an ultimate limit state failure in terms of severity, depending on the degree of inspectability, repairability, and damage tolerance of the structure. This recommended $\beta_{\text {target }}$ range was chosen for use herein primarily to facilitate quantitative comparisons at target indices that might be considered for fatigue design in practice. In particular, the treatment benefit predicted by the model for higher target reliability indices was of interest. Looking at Fig. 11, it can be seen that for this target index range, Bridge I, designed for static strength only, is highly inadequate for fatigue. This finding was consistent with the code-based verification, as well as the observations of bridge designers. Bridge $\mathrm{V}-$ designed to meet the code-based fatigue verification - appears to be somewhat over-designed according to the probabilistic, LEFMbased analysis.

In Fig. 12, curves are presented comparing the reliability indices for the untreated (NT) and treated bridge variants as a function of the steel weight. In this figure, the curves for the treated case correspond with a strategy of full treatment (TS3). Separate graphs are presented for the lower and upper bound series system reliability models. With curves such as these, it is possible to determine the potential savings in steel weight due to post-weld treatment for a given target index. For example, it can be shown that, for the studied tubular truss bridge, the potential steel weight savings due to needle peening using treatment strategy TS3 is $6 \%-13 \%$ for $1.16 \leq \beta_{\text {target }} \leq$ 3.74. Using a similar approach, the potential reduction in tube diameter (of interest for aesthetic reasons) can be estimated. Normally, this reduction is seen to be on the order of a drop to the next available tubular section size.

It was recognized that engineers considering the use of postweld treatment methods for tubular truss bridges may decide to use the improvement in fatigue performance to increase the fatigue life, rather than to reduce the steel weight and/or tube diameter. In order to facilitate a determination of the potential benefit of treatment towards this end, the same probabilistic study results are presented in Figs. 13 and 14 in a slightly different form. In these figures, the fatigue life, $T r$, is plotted as a function of the steel weight, for Bridges I-V, assuming target reliability indices of 3.74 and 1.16.

Looking at Figs. 13 and 14, if the fatigue life of the untreated bridge is taken as the planned service life imposed by the code (70 years), then the service life of an identical, treated bridge can be determined by finding the intersection between the treated (TS3) curve and a vertical line corresponding with the steel weight of the untreated bridge. For $\beta_{\text {target }}=3.74$, the resulting fatigue life improvement was found to range from $250 \%$ to $320 \%$, depending on whether the lower or upper 

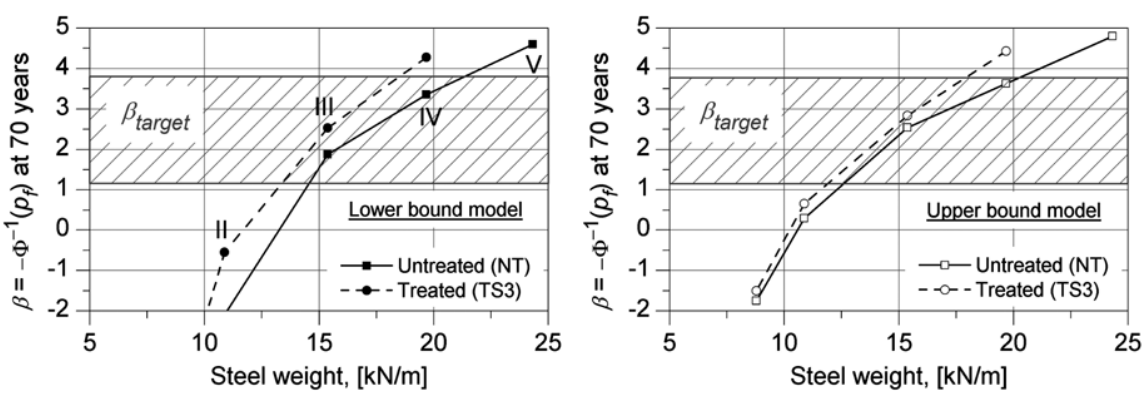

Fig. 12. Reliability versus steel weight for untreated and treated bridge variants.
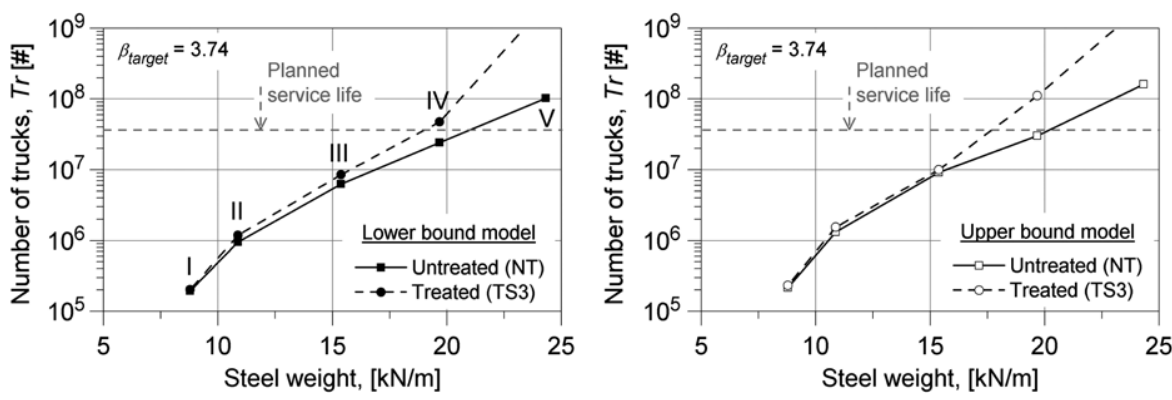

Fig. 13. Fatigue life versus steel weight $\left(\beta_{\text {target }}=3.74\right)$.
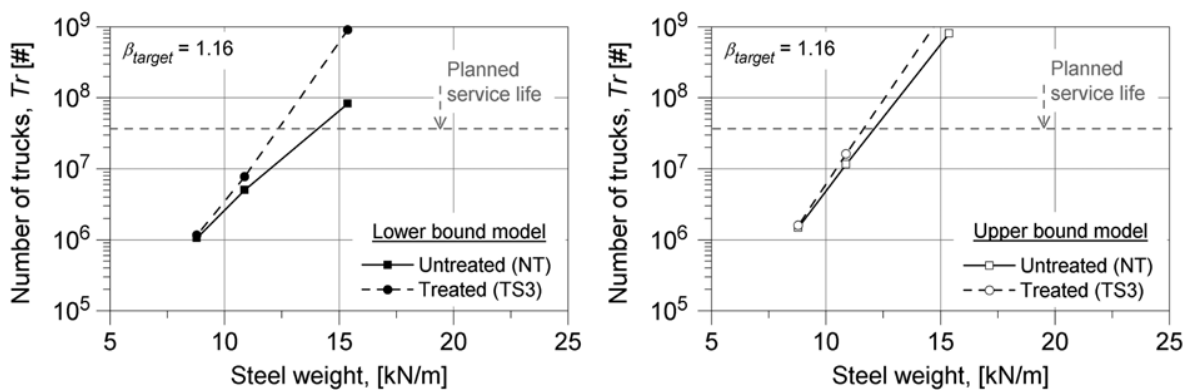

Fig. 14. Fatigue life versus steel weight $\left(\beta_{\text {target }}=1.16\right)$.

bound model is assumed. For $\beta_{\text {target }}=1.16$, the fatigue life improvement was found to range from $120 \%$ to $930 \%$. It should be noted that the fatigue loading simulations used to generate the graphs in Figs. 13 and 14 were stopped at $T_{r} \approx 2 \times 10^{9}$ (if failure had yet not occurred at this point). Thus, the portions of the curves extending above the upper limit of these graphs may represent lower bounds in some cases.

\section{Additional studies}

Following this assessment of the post-weld treatment benefit under "typical" treatment conditions, several additional studies were carried out to determine the sensitivity of the treatment benefit to variations in a number of key parameters. Among these were the treatment coverage, intensity, and uniformity.

For the treatment coverage study, a number of different treatment strategies were compared. In general, the treatment benefit was seen to increase with an increase in treatment coverage. However, often a scenario of diminishing returns was observed, meaning that as the coverage was increased, the incremental benefit of further treatment became less and less. An important finding of this study was the observation that the same treatment benefit could be achieved with a partial treatment strategy (TS4), wherein only Hot-spots 1L, 11L, 1R, and $11 \mathrm{R}$ are treated, as illustrated in Fig. 15. This observation was seen to be true for all of the joints on all of the analyzed bridge variants, assuming typical levels of treatment intensity and uniformity.

The treatment intensity and uniformity studies involved repeating the previously executed probabilistic analyses, assuming different values for the mean and standard deviation of the statistical variable $V A R_{p w t}$. Based on the calibration described earlier using the residual stress measurements from [18], the variable $V A R_{p w t}$ was assumed to be normally distributed with a mean value of 0.5 and a standard deviation of 0.1 for needle peening at typical levels of treatment intensity and uniformity [14,15]. In Figs. 16 and 17, sample results from the treatment intensity and uniformity studies are presented. In Fig. 16, three levels of treatment intensity are compared, namely: $1-$ $\mu\left(V A R_{p w t}\right)=0.75,2-\mu\left(V A R_{p w t}\right)=0.50($ typical $)$, and 

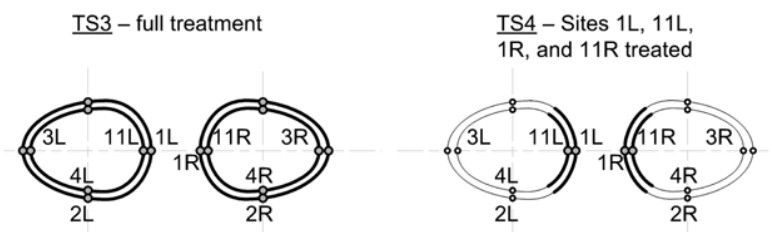

Fig. 15. Full (TS3) and partial (TS4) treatment strategies.

$3-\mu\left(V A R_{p w t}\right)=0.25$. In Fig. 17, three levels of treatment uniformity are compared: $a-\sigma\left(V A R_{p w t}\right)=0.05, b-\sigma\left(V A R_{p w t}\right)=$ 0.10 (typical), and $c-\sigma\left(V A R_{p w t}\right)=0.15$.

Based on the results presented in these figures, it can be concluded that the benefit of treatment is much more sensitive to the intensity than to the uniformity of the treatment. It is believed that the observed small influence of the treatment uniformity should not, however, be interpreted as an indication that treatment quality control is unimportant. In fact, all that the results of this study indicate is that over the investigated range for $\sigma\left(V A R_{p w t}\right)$, the effect of variations in the treatment uniformity is small. This range may not be sufficiently large, however, to consider the variations that may occur if, for example, the treatment is performed by an untrained operator, resulting in large patches at critical hot-spot locations that are effectively untreated, or if one or more of the critical hotspots is completely missed during the treatment process, due to human error on the part of the engineer or the operator.

With this information, however, it can be concluded that the goal of post-weld treatment quality control procedures should not necessarily be the precise characterization of the uniformity of the residual stresses due to the post-weld treatment process, but rather the minimization of the probability of so-called gross

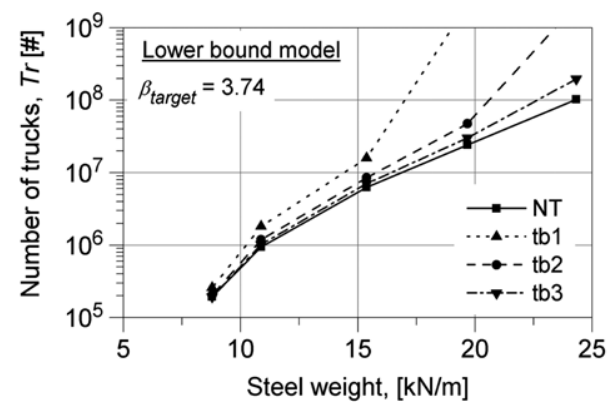

errors. It is believed that proper operator training and the use of existing quality control procedures (such as marking the zones to be treated with a paint that is removed by the treatment and visual inspection) should be sufficient for achieving this basic objective.

Regarding the results of the treatment intensity study, it should be noted that higher treatment intensities were, in fact, often observed in the measured residual stress data from [18], when the residual stresses were measured prior to the application of stress cycles (see Fig. 3). However, when a number of stress cycles were applied prior to measurement, a significant level of residual stress relaxation was observed. This relaxation was seen to stabilize after a relatively small number of cycles. Never the less, it is cautioned that prior to assuming a higher than normal treatment intensity in practice, it should be ensured that the higher measured residual stresses do not relax under cyclic loading.

\section{Conclusions}

Herein, the effect of post-weld treatment on the fatigue performance of tubular truss bridges is assessed using a probabilistic, LEFM-based approach that considers the true, VA loading conditions, as well as the influences of the various potential crack sites on the overall fatigue reliability of the bridge.

By analyzing several variants of a typical tubular truss bridge, it is shown that post-weld treatment by needle peening can result in a significant improvement in fatigue performance for this bridge type. The treatment benefit can be quantified as either a savings in steel weight, on the order of $6 \%-13 \%$, or an increase in fatigue life, on the order of $120 \%-930 \%$; the actual

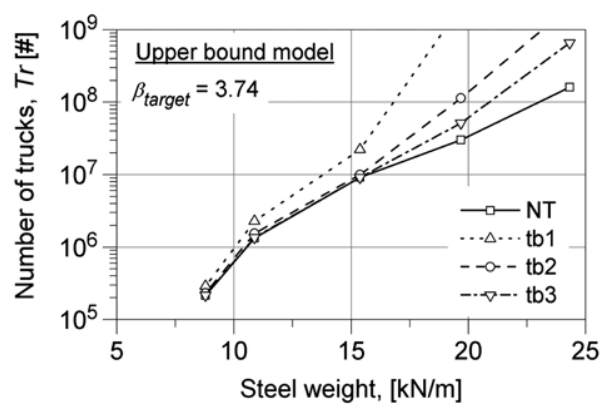

Fig. 16. Effect of treatment intensity on fatigue life (TS3).
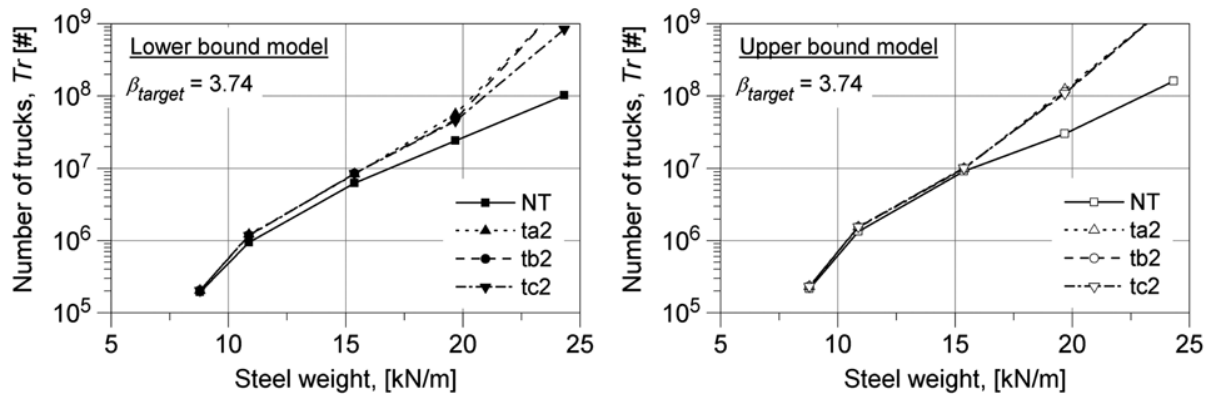

Fig. 17. Effect of treatment uniformity on fatigue life (TS3). 
treatment benefit depending on the true level of correlation between the probabilities of failure of the various potential crack sites on the bridge, as well as the selected target reliability index.

Additional studies show that, for tubular truss bridges similar to the one studied herein, a benefit equal to that of full treatment (at "typical" treatment intensity and quality levels) can be achieved with a partial treatment strategy involving the treatment of Hot-spots 1L, 11L, 1R, and 11R only. Also, the treatment benefit is seen to be more sensitive to the intensity than the uniformity of the treatment. On this basis, it is concluded that proper operator training and the use of existing quality control procedures should be sufficient to ensure an adequate level of treatment quality.

\section{Acknowledgements}

The work presented herein was supported by the Swiss Federal Roads Authority (OFROU Project No. AGB2002/011) and the Swiss National Research Foundation (SNF Grant 200020-101521).

\section{Appendix}

The limit state function, $G(\mathbf{z})$, for the probabilistic single site model employed herein is founded on the Paris-Erdogan crack growth law, modified to consider crack closure effects and a threshold stress intensity factor (SIF) range, $\Delta K_{t h}$, and integrated over a crack depth range, $a_{0}$ to $a_{c}$. Specifically:

$G(\mathbf{z})=N_{c}-N=\int_{a_{0}}^{a_{c}} \frac{\mathrm{d} a}{C \cdot\left(\Delta K_{e f f}^{m}-\Delta K_{t h}^{m}\right)}-N$.

where:

$$
\begin{aligned}
\Delta K_{e f f}= & \operatorname{MAX}\left(K_{a p p, \max }-K_{o p}, 0\right) \\
& -\operatorname{MAX}\left(K_{a p p, \min }-K_{o p}, 0\right)
\end{aligned}
$$

where $K_{a p p, \max }$ and $K_{a p p, \min }$ are the maximum and minimum SIFs due to the applied load; and $K_{o p}$ is the applied SIF at which crack tip opens upon loading. Herein, $K_{o p}$ is calculated as follows:

$K_{o p}=-\left(K_{\text {res }}+K_{p l}\right)$

where $K_{\text {res }}$ is the SIF due to residual stress distribution along anticipated crack path; and $K_{p l}$ is the crack closure SIF. Herein, $K_{p l}$ is calculated using the following empirical expression from [18]:

$K_{p l}=-\operatorname{MIN}\left(\frac{0.2}{\left(1-R_{e f f}\right)}, 0.28\right) \cdot\left(K_{a p p, \max }+K_{\text {res }}\right)$

where $R_{\text {eff }}$ is the effective stress ratio. Specifically:

$R_{\text {eff }}=\frac{K_{a p p, \min }+K_{\text {res }}}{K_{\text {app } \text { max }}+K_{\text {res }}}$.

$K_{\text {res }}$ is calculated at each crack depth increment using the approach proposed in [19].

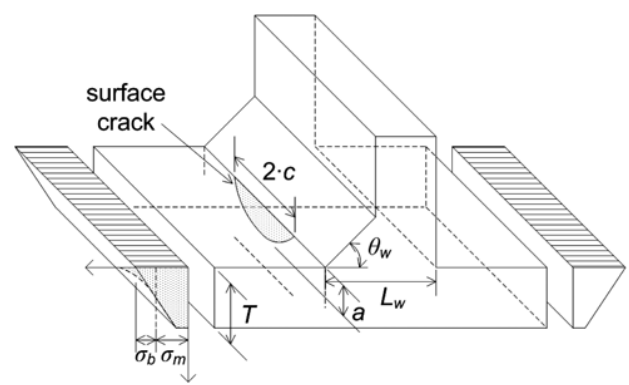

Fig. A.1. Crack at weld toe of T-butt joint.

To solve Eq. (A.2), $K_{a p p}$ is determined using the following expression:

$$
\begin{aligned}
K_{a p p}= & \left(M k_{m} \cdot Y_{m} \cdot(1-\mathrm{DOB})+M k_{b} \cdot Y_{b} \cdot \mathrm{DOB}\right) \\
& \times \sigma_{h s, a p p} \cdot \sqrt{\pi \cdot a}
\end{aligned}
$$

where $\sigma_{h s, a p p}$ is the applied hot-spot stress; $M k_{m}, M k_{b}, Y_{m}$, and $Y_{b}$ are the magnification and correction factors for the bending $\left(\sigma_{b}\right)$ and membrane $\left(\sigma_{m}\right)$ stress cases; and DOB is the degree of bending $\left(=\sigma_{b} /\left(\sigma_{b}+\sigma_{m}\right)\right)$. In using this approach, it is essentially assumed that a weld toe crack anywhere on a tubular joint behaves in the same way as a similar crack in a T-butt joint such as the one in Fig. A.1.

Herein, $M k_{m}$ and $M k_{b}$ are solved using parametric equations from [20]. These require as input the following parameters: $a / T, a / c, L_{w} / T$, and $\theta_{w} . Y_{m}$ and $Y_{b}$ are solved using parametric equations from [21]. These require as input the following parameters: $a / T$ and $a / c$. The DOB is solved using parametric equations from [22], making assumptions for the missing load cases, and ignoring the limits on $\gamma$. These require as input the hot-spot location and the following parameters: $\alpha\left(=2 \cdot L_{c h} / D\right), \beta, \gamma, \tau$, and $\theta_{b r}$.

A one-dimensional crack propagation model is employed herein with the aspect ratio, $a / c$, varied according to a predefined crack shape evolution function wherein the initial aspect ratio, $(a / c)_{0}$, may vary, but this ratio then evolves smoothly, converging on a fixed value of 0.2 at $b / T=$ 0.25 [14].

In order to determine the probabilities of failure of structures comprised of CHS $K$-joints with multiple potential crack sites, lower and upper bound reliability models for series systems are employed herein. Specifically, it is assumed that each $K$ joint can be modelled as a series system with 16 constituent elements, corresponding with each of the hot-spots identified in Fig. 1 (Note: Sites 2L, 4L, 2R, and 4R each occur twice). The lower bound reliability model assumes that the fatigue lives of the individual hot-spots are fully independent [25]. On this basis the probability of failure of the joint is as follows:

$$
\begin{aligned}
p_{f, j o i n t}= & 1-\left(1-p_{f, 1 L}\right) \cdot\left(1-p_{f, 11 L}\right) \times \cdots \\
& \times\left(1-p_{f, 4 R}\right)
\end{aligned}
$$

where $p_{f, j o i n t}$ is the probability of joint failure, $p_{f, 1 L}$ is the probability of failure of Site $1 \mathrm{~L}$, etc. (recall that the reliability index, $\beta=-\Phi^{-1}\left(p_{f}\right)$ ). To determine the probabilities of failure of tubular structures with multiple joints, a similar 
approach is used. The upper bound reliability model assumes full correlation of the fatigue lives of each potential crack site [25], and takes the following form:

$p_{f, \text { joint }}=\operatorname{MAX}\left(p_{f, 1 L}, p_{f, 11 L}, \ldots, p_{f, 4 R}\right)$.

\section{References}

[1] Virlogeux M, Bouchon E, Berthellemy J, Resplendino J. The antrenas tubular arch bridge, France. Structural Engineering International 1997; 97(2):107-9.

[2] Dauner H-G, Decorges G, Oribasi A, Wéry D. The Lully Viaduct, a composite bridge with steel tube truss. Journal of Constructional Steel Research 1998;46(1-3). Paper no. 55.

[3] Manterola J, Gil M-A, Martínez A. Bridge over the Llobregat river (Barcelona, Spain) and bridge over the Escudo river (Cantabria, Spain). In: Proceedings of the 10th international symposium on tubular structures "Tubular Structures X". Madrid: Balkema; 2003. p. 15-9.

[4] Schumacher A. Fatigue behaviour of welded circular hollow section joints in bridges. Thesis no. 2727. École polytechnique fédérale de Lausanne; 2003. http://icom.epfl.ch.

[5] Schumacher A, Nussbaumer A. Experimental study on the fatigue behaviour of welded tubular $K$-joints for bridges. Engineering Structures 2006;28(5):745-55.

[6] Veselcic M, Herion S, Puthli R. Cast steel in tubular bridges-new applications and technologies. In: Proceedings of the 10th international symposium on tubular structures "Tubular Structures X". Madrid: Balkema; 2003. p. 135-42.

[7] Haldimann-Sturm S, Nussbaumer A. Determination of allowable defects in cast steel nodes for tubular bridge applications. International Journal of Fatigue [in press].

[8] Smith IFC, Hirt MA. A review of fatigue strength improvement methods. Canadian Journal of Civil Engineering 1985;12:166-83.

[9] Kirkhope KJ, Bell R, Caron L, Basu RI, Ma K-T. Weld detail fatigue life improvement techniques-Part 1: Review. Marine Structures 1999; 12:447-74.

[10] Haagensen PJ, Maddox SJ. IIW recommendations on the post weld improvement of steel and aluminium structures. Doc. XIII-1815-00. International Institute of Welding; 2004.

[11] Kudryavtsev Y, Kleiman J, Lugovskoy A, Prokopenko G. Fatigue life improvement of tubular welded joints by ultrasonic peening. Doc. XIII2117-06. International Institute of Welding; 2006.

[12] Dubois V. Fatigue de détails soudés traités sous sollicitations d'amplitude variable. Thesis no. 1260. École polytechnique fédérale de Lausanne; 1994.

[13] Manteghi S, Maddox SJ. Methods for fatigue life improvement of welded joints in medium and high strength steels. Doc. XIII-2006-04. International Institute of Welding; 2004.

[14] Walbridge S. A probabilistic study of fatigue in post-weld treated tubular bridge structures. Thesis no. 3330. École polytechnique fédérale de Lausanne; 2005. http://icom.epfl.ch.
[15] Walbridge S, Nussbaumer A. A probabilistic model for determining the effect of post-weld treatment on the fatigue performance of tubular bridge joints. International Journal of Fatigue 2007;29(3):516-32.

[16] Walbridge S, Nussbaumer A. Probabilistic fatigue assessment of postweld treated tubular truss bridges. In: 7th international conference on short and medium span bridges. 2006.

[17] Walbridge S, Nussbaumer A. Probabilistic fatigue analysis of a postweld treated tubular bridge. In: Proceedings of the 11th international symposium on tubular structures "Tubular Structures XI". Quebec City: Taylor \& Francis; 2006. p. 69-75.

[18] Bremen U. Amelioration du comportement à la fatigue d'assemblages soudés : étude et modelisation de l'effet de contraintes residuelles. Thesis no. 787. École polytechnique fédérale de Lausanne; 1989.

[19] Albrecht P, Yamada K. Rapid calculation of stress intensity factors. Journal of Structural Engineering 1977;103(ST2):377-89.

[20] Bowness D, Lee MMK. Prediction of weld toe magnification factors for semi-elliptical cracks in T-butt joints. International Journal of Fatigue 2000;22(5):369-87.

[21] Newman JC, Raju IS. An empirical stress-intensity factor equation for the surface crack. Engineering Fracture Mechanics 1981;15(1-2):185-92.

[22] Connolly MP, Hellier AK, Dover WD, Sutomo J. A parametric study of the ratio of bending to membrane stress in tubular Y- and T-joints. International Journal of Fatigue 1990;1:3-11.

[23] Stacey A, Barthelemy J-Y, Leggatt RH, Ainsworth RA. Incorporation of residual stresses into the SINTAP defect assessment procedure. Engineering Fracture Mechanics 2000;67:573-611.

[24] Porter Goff RFD, Free JA, Tsiagbe WZ. Experimental determination of residual stresses in welded tubular T-joints. Fatigue of Offshore Structures 1988;285-95.

[25] Melchers RE. Structural reliability analysis and prediction. 2nd ed. John Wiley \& Sons; 1999.

[26] Zhao XL, Herion S, Packer JA, Puthli RS, Sedlacek G, Wardenier J. et al. Guide no. 8-Design guide for circular and rectangular hollow section welded joints under fatigue loading. CIDECT. Cologne; 2001.

[27] Romeijn A, Karamanos SA, Wardenier J. Effects of joint flexibility on the fatigue design of welded tubular lattice structures. In: 7th international offshore and polar engineering conference. 1997.

[28] American Welding Society. AWS D1.1-2000 Structural Welding CodeSteel. Miami; 2000.

[29] Stephens RI, Fatemi A, Stephens RR, Fuchs HO. Metal fatigue in engineering. 2nd ed. John Wiley \& Sons; 2001.

[30] Shetty NK, Baker MJ. Fatigue reliability of tubular joints in offshore structures: Fatigue loading. In: 9th international conference on offshore mechanics and artic engineering, vol. II. 1990. p. 33-40.

[31] Kunz P, Hirt MA. Grundlagen und Annahmen für den Nachweis der Ermüdungsfestigkeit in den Tragwerksnormen des SIA. Doc. D 076. Swiss Society of Engineers and Architects (SIA); 1991.

[32] Swiss Society of Engineers and Architects (SIA). SIA 260/261/263:2003 (Basis for structural design/Actions on structures/Steel structures). Zurich; 2003.

[33] European Committee for Standardization. EN1990 — Basis of structural design. Brussels; 2002. 